\title{
Sediment Variation Characteristics of Major Rivers in the Middle Reaches of the Yellow River
}

\author{
Yaxi Cai ${ }^{*}$, Xiaodong Yang² \\ 1Shaanxi Provincial Land Engineering Construction Group Weinan Branch, Weinan 714000, Shaanxi Province, China \\ ${ }^{2}$ Xi'an Water Supply Corporation Limited, Xi'an 710082, Shaanxi Province, China \\ *Corresponding author: Yaxi Cai, zsjcyxczl@163.com
}

\begin{abstract}
The sediment sequence analysis of Mann-Kendall method based on major rivers of 10 hydrological station in the middle reaches of the Yellow River ${ }^{[1]}$. The results show that: The main rivers in the middle reaches of the Yellow River hydrologic station sediment overall showed a trend of decreased significantly. Sediment discharge of all stations except Gao Jiachuan station have reached the maximum in 1956-1969s ${ }^{[2-3]}$. Among various hydrologic station sediment discharge of inter-generational are generally shows the tendency of reducing year by year. Calculate the sediment transport of major river basin of Yellow River, which average is 0.63 .
\end{abstract}

Keywords: The middle reaches of the Yellow River; Sediment load; Trend analysis

Publication date: September 2021; Online publication: September 30, 2021

\section{Introduction}

River system is a dynamic system affected by climate change and human activities, and water and sediment change are the most active part of the system. The study of river water and sediment change provides important information for soil erosion and river sediment deposition, which is an important research content of river system. The middle reaches of the Yellow River are the main sediment producing area of the Yellow River Basin, which is mainly located between Hekou town and Longmen. "The trouble of the Yellow River lies in its excess sand" ${ }^{[4]}$. Since the late 1950s, the country has always regarded this area as the key control area of water and soil loss in the Yellow River Basin, and has achieved very remarkable results in more than 40 years. The amount of yellow mud and sand from the sandy and coarse sand area has been greatly reduced ${ }^{[5-6]}$. According to data statistics, the average annual sediment load of Sanmenxia station on the Yellow River is about 1.59 billion t, while average annual sediment load from 1961 to 2000 was 1.12 billion $\mathrm{t}$, and the average annual sediment load in recent 10 years (2001-2010) was 360 million $\mathrm{t}^{[7]}$.

The Yellow River is a sediment laden river, and its riverbed erosion and deposition evolution have a high-order nonlinear response to the incoming water and sediment in the basin ${ }^{[8]}$. Many studies have been carried out on the variation of water and sediment in the Yellow River ${ }^{[9-15]}$, but the research on the variation of water and sediment in the upper and middle reaches of the Yellow River in recent years is few and not systematic. At the same time, the water and sediment of the Yellow River is always a dynamic change system, especially with the implementation of the project of returning farmland to forest and grass and the large-scale ecological restoration construction of the Loess Plateau, the water and sediment change of the Yellow River has increased uncertainties, so there are still many scientific problems to be solved.

Therefore, based on the measured daily sediment transport data of 10 hydrological stations of the main rivers in the middle reaches of the Yellow River from 1956 to 2010, this paper analyzes the interannual variation trend of sediment transport at each hydrological station, simulates the runoff and sediment 
transport of each basin, and calculates the sediment transport ratio. It is expected to provide a scientific basis for the formulation of the control countermeasures of the Yellow River and provide a certain basis for the in-depth study of river water and sediment changes and their possible influencing factors.

\section{Overview of the study area}

The more sediment and coarse sediment region in the middle reaches of the Yellow River is composed of Hekou town and Longmen, and most of its tributaries such as Wuding River, Huangfuchuan River and Kuye River, are located between Hekou town and Longmen. In order to facilitate the research on a longterm scale, this paper takes Huangfu River, Gushan River, Wuding River, Tuwei River, Kuye River, Dali River and Jialu River in the middle reaches of the Yellow River as the research area. The total drainage area is $47100 \mathrm{~km} 2$. The overview of the study area is shown in Figure 1.

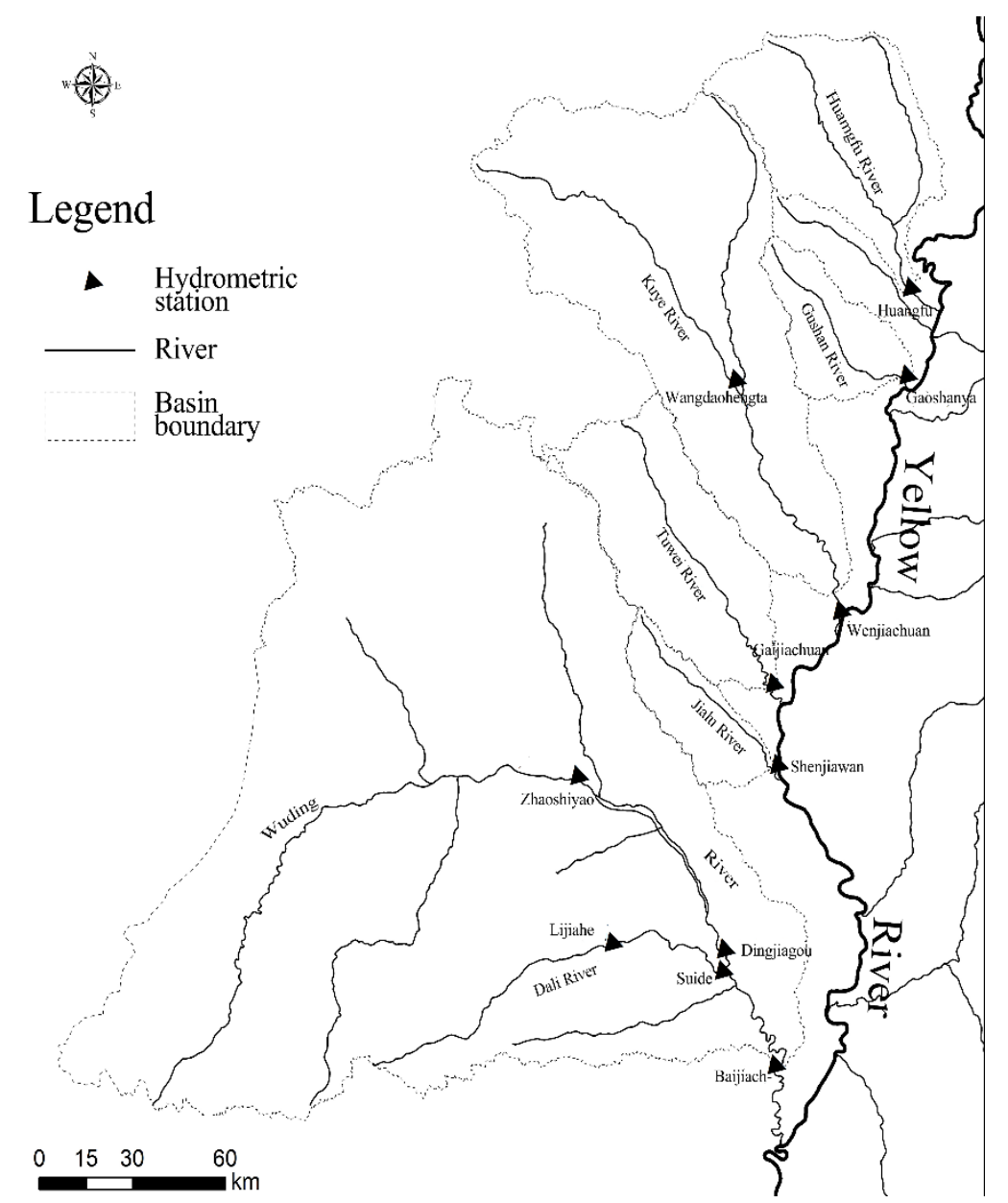

Figure 1. Hydrological station network and river system in the study area

\section{Data sources and research methods}

\subsection{Data sources}

The data are based on the measured daily runoff and sediment runoff of 10 hydrological stations, such as Huangfu River, Gushan River, Wuding River, Tuwei River, Kuye River, Dali River and Jialu River in the middle reaches of the Yellow River from 1956 to 2010.

\subsection{Data analysis and processing methods}

The descriptive and statistical analysis of samples was carried out by SPSS 16.0 software. The statistical eigenvalues include mean value, standard deviation, variation coefficient, etc. 


\section{Results and analysis}

\subsection{Analysis on interannual variation of sediment discharge at main hydrological stations}

This section mainly studies the sediment transport variation of 10 hydrological stations in the middle Reaches of the Yellow River, including Huangfu River, Gushan River, Wuding River, Tuwei River, Kuye River, Dali River and Jialu River. The series values and linear fitting relationship of sediment discharge of the main hydrological stations in the above basins from 1956 to 2010 are shown in Figure 2. In the whole time series, the annual sediment discharge of each hydrological station shows an obvious decreasing trend as a whole.

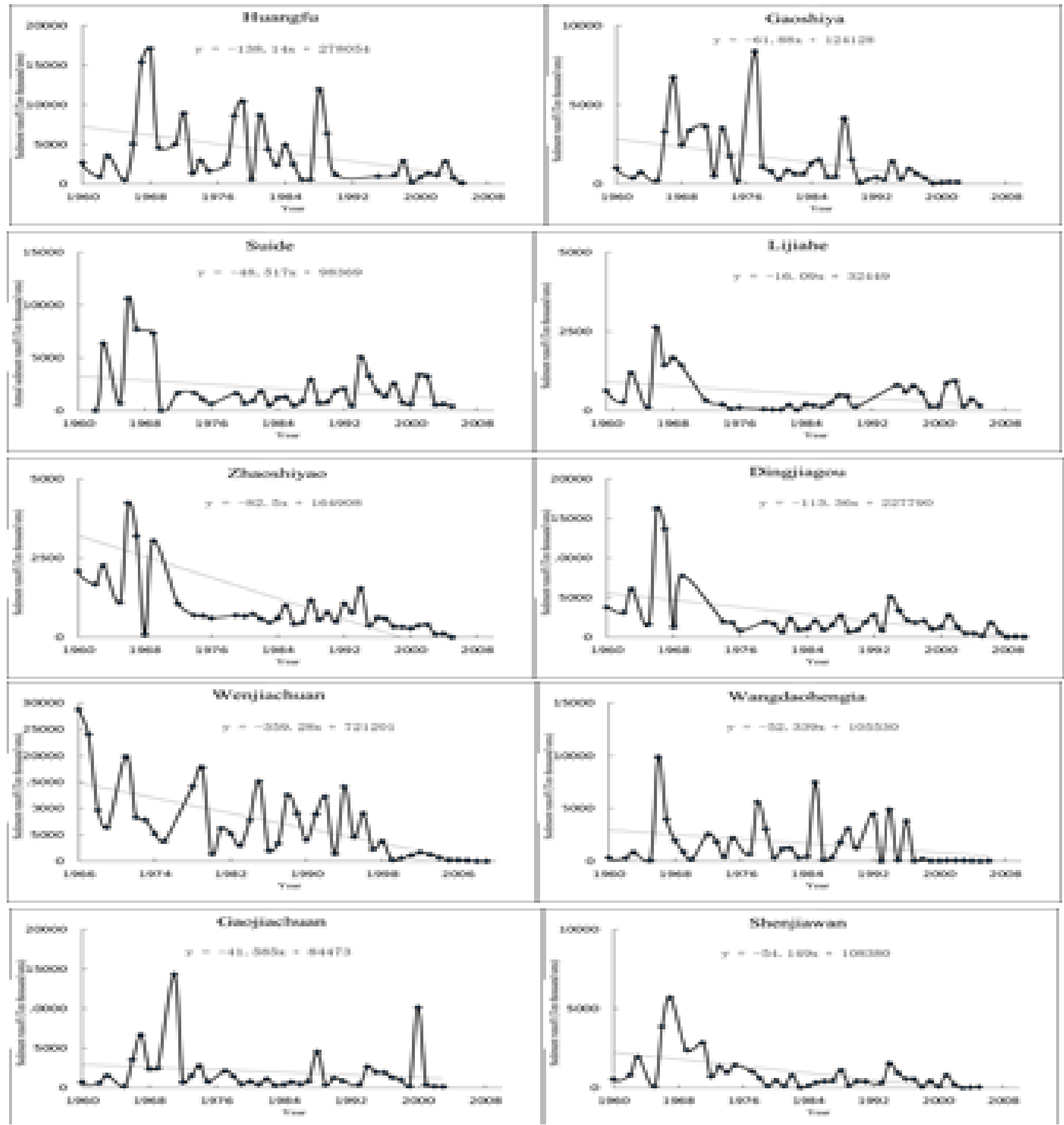

Figure 2. Annual sediment discharge of main hydrological stations of important rivers in the middle reaches of the Yellow River 


\subsection{Relationship of runoff and sediment transport at main hydrological stations in the middle Reaches of the Yellow River}

According to the measured runoff and sediment transport data of 10 main hydrological stations in the middle Reaches of the Yellow River, the relationship between annual runoff and sediment transport in the main basins of the middle Reaches of the Yellow River is fitted, as shown in Table 1. It can be seen from Table 1. that the runoff sediment transport relationship of each basin is linear, and the correlation coefficient is good.

Table 1. Relationship between annual runoff $(\mathrm{x})$ - annual sediment transport ( $\mathrm{y}$ ) of main rivers in the middle reaches of the Yellow River

\begin{tabular}{ccccc}
\hline $\begin{array}{c}\text { Serial } \\
\text { number }\end{array}$ & Rivers & $\begin{array}{c}\text { Hydrological } \\
\text { station }\end{array}$ & Relational formula & $\begin{array}{c}\text { Correlation } \\
\text { coefficient R }\end{array}$ \\
\hline 1 & Dali River & Suide & $\mathrm{y}=0.4291 \mathrm{x}-3310.90$ & 0.65 \\
2 & Gushan River & Gaoshiya & $\mathrm{y}=0.3257 \mathrm{x}-700.66$ & 0.85 \\
3 & Huangfu River & Huangfu & $\mathrm{y}=0.3712 \mathrm{x}-741.19$ & 0.80 \\
4 & Jialu River & Shenjiawan & $\mathrm{y}=0.3952 \mathrm{x}-1095.70$ & 0.89 \\
5 & Kuye River & Wangdaohengta & $\mathrm{y}=0.1720 \mathrm{x}-1272.90$ & 0.43 \\
6 & Kuye River & Wenjiachuan & $\mathrm{y}=0.2154 \mathrm{x}-3845.00$ & 0.72 \\
7 & Tuwei River & Gaojiachuan & $\mathrm{y}=0.1259 \mathrm{x}-2572.80$ & 0.48 \\
8 & Wuding River & Dingjiagou & $\mathrm{y}=0.0437 \mathrm{x}-1778.40$ & 0.50 \\
9 & Wuding River & Zhaoshiyao & $\mathrm{y}=0.0903 \mathrm{x}-2468.50$ & 0.56 \\
10 & Xiaoli River & Lijiahe & $\mathrm{y}=0.5428 \mathrm{x}-801.38$ & 0.79 \\
\hline
\end{tabular}

\subsection{Study on sediment transport ratio in the middle reaches of the Yellow River}

In recent years, the wide implementation of dam and reservoir projects in the middle reaches of the Yellow River has significantly changed the sediment yield process of the basin. Under natural conditions, the sediment transport ratio in the loess hilly and gully region is generally close to 1 , so the sediment yield modulus can be used instead of the erosion modulus. The implementation of dam and reservoir projects has significantly changed the process of erosion and sediment transport. Generally, the following formula can be used to calculate the basin erosion.

Erosion modulus $=$ sediment transport modulus $/$ sediment-delivery ratio

This study collected the siltation data of reservoirs and backbone dams (silt dams) of important rivers in the middle reaches of the Yellow River. The siltation volume of dam reservoir is the total siltation amount from the construction of dam to 2011. The annual siltation volume from 1991 to 2011 was calculated by reduction calculation using the average annual rainfall.

However, due to the large number of medium-sized and small silt dams, the siltation volume cannot be ignored, but it is impossible to make a clear investigation. This study adopts the following methods: Firstly, typical river basins are selected to investigate the configuration ratio of backbone dams, medium-sized dams and small dams, as well as the control area ratio of backbone dams, medium-sized dams and small dams in typical river basins. The survey shows that: The configuration ratio of backbone dam, mediumsized dam and small dam of silt dams in this area is 1:1.7:3.5, while the control area ratio of main dam, medium-sized dam and small dam is generally 8.9:2.1:1. Therefore, the reduction calculation is based on the siltation volume volume of the backbone dam, and then multiplied by 1.8 , which is the reduction 
adjustment coefficient of medium-sized dam and small dam. After calculation, the average sediment transport ratio of the main rivers in the middle reaches of the Yellow River is 0.63. Specific calculation results are shown in Table 2.

Table 2. Calculation results of sediment transport ratio of major rivers in Yulin City

\begin{tabular}{ccccc}
\hline Station name & $\begin{array}{c}\text { Sediment } \\
\text { transport volume } \\
\text { / 10000 t }\end{array}$ & $\begin{array}{c}\text { Deposit volume / } \\
\mathbf{1 0 0 0 0 ~ t}\end{array}$ & $\begin{array}{c}\text { Erosion amount / } \\
\mathbf{1 0 0 0 0 ~ t}\end{array}$ & $\begin{array}{c}\text { Sediment } \\
\text { transport ratio }\end{array}$ \\
\hline Gaojiachuan & 1713.51 & 271.09 & 1984.60 & 0.70 \\
Gaojiabao & 268.17 & 87.71 & 355.88 & 0.57 \\
Suide & 2174.56 & 1119.47 & 3294.03 & 0.56 \\
Shenjiawan & 875.37 & 223.42 & 1098.79 & 0.64 \\
Wangdaohengta & 1213.76 & 48.35 & 1262.10 & 0.72 \\
Lijiahe & 1244.07 & 480.79 & 1724.86 & 0.37 \\
Zhaoshiyao & 1382.96 & 1243.97 & 2626.93 & 0.44 \\
Gaoshiya & 1208.44 & 298.25 & 1506.70 & 0.59 \\
Huangfu & 3203.57 & 193.59 & 3397.16 & 0.87 \\
Wenjiachuan & 6779.99 & 274.16 & 7054.15 & 0.82 \\
\hline
\end{tabular}

\section{Conclusion and discussion}

(1) The sediment discharge of 10 hydrological stations of the main river in the middle reaches of the Yellow River showed an obvious decreasing trend from 1956 to 2010, which was in line with the linear fitting relationship.

(2) The runoff sediment transport relationship of the main river in the middle reaches of the Yellow River is linear, and the correlation coefficient is good.

(3) Due to the wide implementation of dam and reservoir projects in the middle reaches of the Yellow River, the sediment yield process of the basin has been significantly changed. It is found that the average sediment transport ratio of the main rivers in the middle reaches of the Yellow River is 0.63.

Soil and water conservation in the middle reaches of the Yellow River began in the 1950s, and became larger and faster after the 1980s. The implementation of water conservancy and soil conservation measures changed the law of water and sediment production in the region, resulting in the sharp decrease of sediment transport in the region in 1985. Human activities such as soil and water conservation, ecological environment restoration and water conservancy project construction are the main driving factors leading to the sharp reduction of water and sediment in the middle reaches of the Yellow River. However, how various factors affect the change of water and sediment still needs further research and exploration.

\section{Disclosure statement}

The author declares no conflict of interest.

\section{References}

[1] Mann HB, 1945, Nonparametric Tests Against Trend. Econometrica, 13(3): 245-259.

[2] Kendall MG, 1975, Rank Correlation Measures. London: Charles Griffin.

[3] Gao PX, Zhang CX, Mu M, et al, 2010, Trend and Change-Point Analyses of Streamflow and 
Sediment Discharge in Yellow River Mainstream during 1950-2005. Hydrological Sciences Journal, 55(2): 275-285.

[4] Ren ME, 2006, Sediment Transport of the Yellow River: Past, Present and Future, Advances in Earth Science, 21 (6): 551-563.

[5] Yu T, Deng YX, Fu G, et al., 2007, Analysis on the Variation Characteristics and Causes of Sediment Transport in the Yellow River in Recent 50 Years, Yellow River, 29(12): 27-28.

[6] Yao WY, Xu JH, Ran DC, et al., 2011, Analysis and Evaluation of Water and Sediment Change in the Yellow River Basin. Zhengzhou: The Yellow River Water Conservancy Press, 24-25.

[7] Zhao GJ, Mu XM, Tian P, et al., 2012, Analysis on Variation Trend and Influencing Factors of Water and Sediment in the Middle Reaches of the Yellow River in Recent 60 Years. Resources Science, 34(6):1070-1078.

[8] Gao H, Yao WY, Zhang XH, 2005, Analysis of Recent Water and Sediment Changes in the Upper and Middle Reaches of the Yellow River. Journal of North China University of Water Resources and Electric Power, 30 (5) :8-12.

[9] Wang LN, Wang Y, Gao P, et al., 2008, Analysis on Variation Characteristics and Trend of Sediment in Coarse Sediment Concentration Source Region of loess Plateau. Bulletin of Soil and Water Conservation, 28(2): 12-16.

[10] Wang CR, Ran DC. 2002, Hydrologic Analysis of Water and Sediment Change in Sanchuan River Basin. Bulletin of Soil and Water Conservation, 22(6): 15- 19.

[11] Xu JX, 2010, Variation Trend and Causes of Water and Sediment in the Middle Reaches of the Yellow River from 1997 to 2007. Journal of Soil and Water Conservation, 24 (1): 1-7.

[12] Wang HJ, Yang Y, et al., 2007, Stepwise decreases of the Huanghe (Yellow River) sediment load (1950-2005); Impacts of climate change and human activities. Global and Planetary Change, 2007, 57(3-4): 331-354.

[13] Ran DC, 2000, A Review on the Variation of Water and Sediment in Helong Section of the Middle Yellow River. Journal of Sediment Research, (3): 72-81.

[14] Xu JX, Sun J, 2003, Effects of Precipitation Change and Human Activities on Runoff Flux from the Yellow River to the Sea in Recent 50 Years. Advances in Water Science, 14(6): 690-695.

[15] Ran DC, Liu LW, Zho LY, et al., 2000, Soil and Water Conservation and Sediment Change between Hekou Town and Longmen In the Middle Reaches of the Yellow River. Zhengzhou: The Yellow River Water Conservancy Press, 1-274. 